\title{
The Application of Stratified Teaching Approach to Vocational College English
}

\author{
Xianglong Kong \\ Shanghai Medical Instrumentation College, Shanghai 200093, China \\ kx1302213@163.com
}

\begin{abstract}
Through the analysis of the teaching mode in higher vocational colleges, this paper advocates the practice of implementing the stratified teaching approach on the basis of the current English teaching situation and its features. Meanwhile the significance and effective ways of stratified teaching in English are studied so as to foster excellent professionals with higher skills and compound knowledge.
\end{abstract}

Index Terms - stratified teaching approach, higher vocational and professional college, English

\section{Introduction}

There exists huge discrepancy among vocational college students in English learning, which requires the college teachers to be proficient in application of the stratified teaching approach while giving their lectures [1]. Additionally, after strengthening the attention paid to students and conducting a comprehensive understanding of students' learning situation, Reasonable level classification amid students should be figured out in accordance with their abilities of English learning and their individual characteristics. Then discrepant learning objectives and flexible learning evaluations can be distributed to different groups, which, in turn, can actively play the subjectivity of the students and encourage students' personality development. Only through implementing stratified teaching the principle of people-orientated education can be fully reflected, enhancing the comprehensive quality of students effectively.

\section{The Necessity of Implementing the Stratified Teaching}

The practice of stratified English teaching approach in vocational colleges caters to the demand of teaching reform. The stratified teaching approach truly awards the role of subjectivity to the students in the process of English teaching; meanwhile, it places the students as the center of teaching process so as to excavate their potentials, subsequently, the initiatives and enthusiasm of students autonomous learning can be aroused; consequently, it is an effective approach worthy of promoting.

"Stratified teaching" refers to an approach in which diverse teaching strategies are available for English teachers in terms of students' discrepancy in the ability of learning, and which is called as a method of teaching students in accordance with their aptitude [2]. This teaching style is in line with the requirements of new era, absorbing the merits of the conventional mode of teaching. Based on the advantages of conventional one, it leads some reform and innovation in the institution. The approach necessitates the hierarchical reform on both guiding ideology and modes of instruction; it is crucial that teaching content of English be deepened gradually so that students can have enough confidence to learn. Only through this way can students' learning initiative and enthusiasm be motivated, which, in turn, enhances their thinking ability. Eventually, the process of English learning can become a virtuous cycle.

The instructors are regarded as the principal part in the conventional teaching mode, which possesses the inherent limitations to ignore the students' individual development [3]. It is widely admitted that the traditional teaching mode in some sense has its value of existence; however, it disregards the differences among students, impeding their individual growth. In the new wave of teaching reform, most colleges are actively exploring brand-new instructing modes, truly regarding the students as the center of learning, advocating the individuality growth of students and adopting the method of teaching students in accordance with their aptitude. Meanwhile, great achievements in promoting the all-round development of students have been attained during this period. Thereby, there is no denying fact that colleges should make courageous attempt in teaching reform to adopt the stratified teaching approach so as to truly realize the quality of education.

\section{The Strengths of Stratified Teaching}

Firstly, the individual discrepancies of students can be fully got attention. This approach requires the instructors to place the students as the principal part in teaching process, observing the individual discrepancies among students. In the process of implementing the reform of educational system, individual growth should be fully taken into consideration [4]. Then distinct teaching modes can be put into the practice in accordance with the individual differences. The entire progress of all students can be made by assuring each student to get a suitable teaching mode. The educational fundamentality is to propel the individual growth and that is why we actively advocate this teaching mode.

Secondly, cooperative learning among students can be enhanced. Cooperative learning is a new attempt in stratified teaching. Namely, reasonable classifications in students should be made in term of their discrepancies so as to make sure their mutual cooperation. Each one is bound to be responsible for not only his performance but also the whole group, which requires all members within the group have to help mutually, more importantly, students good at learning are obliged to give hands to those who have terrible performance in their learning. Consequently, they all can complete their 
tasks assigned by the teacher through working together. This teaching method not only strengthens the exchange and cooperation between students but improves their academic performance as well. The delight in learning can be got in the process of implementing the stratified teaching mode. Most significantly, they can greatly improve their English due to their keen interest in learning English taken from the stratified teaching.

Thirdly, the students' principal status can be guaranteed in the learning process. What the stratified teaching mode really reflects is not how the instructors to lecture but how the students get the knowledge by themselves. The conventional teaching mode gives the emphasis on instructors' performance and their skills, discounting the students' subjectivity and overstating the instructors' role. The stratified teaching, conversely, focuses on how to motivate the students' potentials. If taking initiatives to learn English, they are bound to gain excellent performance. Moreover, through stratified teaching mode each student may always feel to be paid close attention so that they can strive to learn all the time.

\section{The Pattern of Stratified Teaching in Higher Vocational Colleges}

Firstly, making stratification in students; stratifying students is the first step to implement hierarchical education. The stratification in students can be made only after the instructors' close observation and mastering students' real situation. Students in higher vocational colleges tend to be stratified into three groups called group A, group B and group C.

Students in group A, generally speaking, master well-knit foundation of English, possessing strong desire to acquire knowledge; thereby, as fast-learners, they can explore to learn something new autonomously.

Students in group B generally have certain English foundation, possessing great potentials in English learning; their initiatives in learning English are absent due to the shortage of delight in learning.

Those in group $\mathrm{C}$ averagely are weak in their English foundation, having bulky obstacles in learning because of not only having no correct learning methods but also their absence in ability to learn autonomously.

Secondly, making stratification in teaching objectives; only by establishing clear objectives, students tend to be motivated. In the process instructors are obliged to direct them to set specific and suitable learning objectives, inspiring their learning enthusiasm according to different groups. Group A, for instance, should cultivate their ability to learn independently and innovatively; Group B students have to consolidate their foundation and stimulate their enthusiasm in learning English; ones in group $\mathrm{C}$, however, have to learn fundamental knowledge and find effective methods, establishing enough confidence in learning English. Each student' ability can be improved by the stratification in teaching objectives.

Thirdly, making stratification in evaluation system of learning; making stratification in evaluation system actually aims to check whether students in different groups make any progress in their learning ability and knowledge, compared with the original level before stratification. It is unequal to measure all students using the same evaluation system. What's more, any student making progress should be courage and praised. The instructors should evaluate not only their academic performance but also their learning attitude and habit to make a comprehensive and objective outlook.

\section{Implementation Strategy for Stratified Teaching Approach}

\section{A. guarantee in institution}

Stratified Teaching Approach is characterized by large size and extensive objects, including freshmen in the whole college, which involves student management, textbook use, teacher arrangement and other aspects. In this case, a good effect for Stratified Teaching Approach calls for an integrated management system, formulation of regulations for clearly specifying various requirements for level-based teaching, such as significance, principle and methods for teaching by levels [5]. Efforts shall be made to enable all the levels such as the college's Academic Affairs Office, departments of the students, teachers involved in level-based teaching to have a clear understanding of their own responsibilities in a bid to make all the parties involved make concerted efforts in English level-based teaching and ensure the implementation effect of level-based teaching.

\section{B. Guarantee in management}

As Stratified Teaching Approach needs to break the boundary of classes, which will lead to inconvenient management objectively, it is indispensable for level-based teaching to have relevant departments, teachers and academic affairs department to cooperate in class division, adjustment and teaching management.

Firstly, divide the levels in a scientific and reasonable way. Scientific and reasonable level division is a prerequisite and foundation for ensuring a sound level-based teaching. Full consideration shall be given to the students' attitude, character, interest and other psychological factors. The level division for students shall be based on the assessment of freshmen by combining their scores of college entrance examination. Three levels of $\mathrm{A}, \mathrm{B}$ and $\mathrm{C}$ will be divided according to their learning abilities, learning habits and learning results by breaking the class boundary. The quantity and requirements for various levels shall be defined. The students can move to the higher or lower levels in line with their own scores and requests, but such moving to other levels shall not be frequent. If the level-based teaching is implemented based on the existing natural classes, there will be problems in scheduling, teacher resource and teacher arrangement etc., therefore, practicing level-based teaching in various departments respectively shall be a good solution for facilitating effective teaching management.

Secondly, formulate scientific, reasonable and available teaching objectives. Formulation of scientific, reasonable and available teaching objectives can play a role in teaching 
positioning, orientation and excitation so as to strengthen the purpose and pertinence. Second, training and assessment system are also carried out based on levels. Even slight improvement is achieved for students' learning level, encouragement and positive affirmation shall be given to them in due time.

Thirdly, keep a rigorous management and a serious study style. Level-based teaching has broken the teaching of natural classes. As the students involved in level-based teaching come from various classes, resulting in trouble of student management. Some students may dodge to be absent from class, leading to low attendance. On the one side, teachers need to enhance the students' collective sense of belonging. On the other side, the inefficiency in teaching management needs relevant measures to be taken by the college's academic affairs office and various departments.

\section{Guarantee in teaching}

Firstly, different teaching strategies are adopted for various levels. Before level-based teaching, teachers face students with different levels in English, so teachers give lessons to those students with medium level. After dividing the levels, the teachers' burden is not mitigated but aggravated. The teaching materials and teaching methods shall be changed accordingly so as to avoid adoption of unified teaching materials and unchangeable teaching methods. Classes with different levels have different requirements for teachers, which needs teachers to carefully devise their teaching activities, choose suitable methods and approaches for students with different levels, learn about the students' actual needs, concern about their progress, reform their teaching patterns, give full play to their initiative in learning and form a successful incentive mechanism in a bid to ensure each student to make progress.

For students at Class A, teaching materials with specific difficulty shall be adopted firstly, with the learning goal higher than the present level. For example, if they are not allowed to take part in PRETCO in the first semester, they may be encouraged to participate in CET-4 in the second semester. To assign them challenging learning tasks can fully mobilize their enthusiasm for learning. Second, in teaching method, as students of Class A has certain foundation in grammar and vocabulary, emphasis shall be placed on training of language proficiency to avoid excessive use of traditional method-translation but focus on key points in grammar and vocabulary, otherwise it may make students of Class A lose their interests in learning and cause the level division to be meaningless.

Students of Class B are those who have medium level in natural classes and have a specific English knowledge and learning ability, so, it is much easier for teachers to grasp the teaching of Class B. They endeavor to improve various abilities in English in line with the syllabus. Nevertheless, for students of Class B, they also need to choose suitable teaching materials and replenish with important knowledge of high school appropriately. Moreover, outstanding students are encouraged to move into Class A so as to arouse the initiative of students in Class B for learning.

Students of Class C not only lack English knowledge, but also are poor in learning attitude, habit and learning strategy, therefore, Class C students need to focus on learning of English basic knowledge. The students' learning attitude, learning motivation, interest and character etc. have an impact upon the students' learning, so, during the teaching, teachers need to pay particular attention to the emotional factor of Class C students since the students' emotional factor has a direct influence on their learning behavior and learning result. How to eliminate the negative attitude of Class $\mathrm{C}$ students is the key for level-based teaching. At the beginning of level division, the teachers shall provide correct guidance to Class $\mathrm{C}$ students, pay close attention to their learning mentality, teach them about effective learning tactics, develop their abilities in independent learning and enable them to be aware of their progress in an effort to enhance their confidence in English learning.

Secondly, Implement strict management and enhance the students' collective sense of belonging. As mentioned earlier, level-based teaching will make it inconvenient for student management objectively due to breaking the boundary of natural classes, so, on the one hand, teachers have to shoulder heavy responsibilities and ensure the students' classroom attendance; on the other hand, they need to attract the students to stay in class by optimizing their teaching at class. In addition, as the students come from different majors, they stay in the same classroom temporarily only when they take an English class, therefore, teachers need to make use of various strategies for enhancing the classes' cohesion as a collective and boost their collective sense of belonging.

\section{Conclusion}

In higher vocational college English teaching, instructors can not only motivate students' learning enthusiasm and initiatives but also arouse their productive thinking, through adopting the stratified teaching and research- oriented learning. In the class the learner are willing to discuss mutually and the ability to use the language to communicate each other can be formed as well. However, the instructors have to grasp the degree of stratification in students during the process, giving necessary guidance in an appropriate time.

\section{References}

[1] LiHua, Liu, LiXia Tang. The Application of Interactive Teaching Method in vocational college oral English teaching. Vocational and Technical Education, 2010, (35).

[2] Gan Wang, Discussion on How to Optimize the Teaching Method in English. Liberal arts navigation (early), 2010, (11).

[3] Lin Ma, The Application of Discourse Teaching Method in English Reading Teaching. Science \& Technology Information, 2010, (33).

[4] YueGao, the Application of Communicative Approach in College English Intensive Reading Class. Journal of Chifeng College, 2010, (11).

[5] Davis, E. Success in English Teaching. Shanghai: Shanghai Foreign Language Education Press, 2002, ,46)

[6] D.Gardner - L. Miller Establishing Self-access from theory to practice. 2002, (61) 